\title{
Alçakgönüllülük Ölçeğinin Türkçe Formu: Geçerlik ve Güvenirlik Çalışması*
}

\author{
Hakan SARIÇAM** \\ Dumlupınar Üniversitesi, Eğitim Fakültesi, 43100 Kütahya/ Türkiye
}

Doç. Dr. Ahmet AKIN

Sakarya Üniversitesi, Eğitim Fakültesi, Eğitimde Psikolojik Hizmetler ABD, Hendek / Sakarya / Türkiye

\section{Emel GEDIKSSIZ}

Sakarya Üniversitesi, Eğitim Bilimleri Enstitüsü, Eğitimde Psikolojik Hizmetler Yüksek Lisans Öğrencisi,

Hendek / Sakarya/ Türkiye

\section{Ümran AKIN}

Sakarya Üniversitesi, Eğitim Bilimleri Enstitüsü, Eğitimde Psikolojik Hizmetler Doktora Öğrencisi, Hendek / Sakarya/ Türkiye

\section{Özet}

Bu araştırmanın amacı Elliott (2010) tarafından geliştirilen Alçakgönüllülük Ölçeğini Türkçeye uyarlamak ve ölçeğin geçerlik ve güvenirlik analizlerini yapmaktır. Araştırmaya farklı 2 üniversiteden $(289+359)$ toplam 648 üniversite öğrencisi

*Bu makale 3-5 Mayıs 2012 tarihlerinde İstanbul Teknik Üniversitesinde gerçekleştirilen International Counseling and Education (ICE-C 2012) Konferansında sunulan bildirinin genişletilmiş halidir.

** Sorumlu Yazar. Tel: +90 $3488142662 \quad$ E-posta: hakansaricam@gmail.com

(C) 2012 Kalem Eğitim ve Sağlık Hizmetleri Vakfı. Bütün Hakları Saklıdır. ISSN: 2146-5606 
katılmıştır. Ölçeğin psikometrik özellikleri, test-tekrar test, iç tutarlık, açımlayıcı ve doğrulayıcı faktör analizi ve ölçüt bağıntılı geçerlik yöntemleriyle incelenmiştir. Ölçüt bağıntılı geçerlik için Alçakgönüllülük Ölçeği ile birlikte Affedicilik Ölçeği kullanılmıştır. Açımlayıcı faktör analizi sonucu KMO örneklem uygunluk katsayısı .71.4, Barlett testi $\chi 2$ değeri 478,827 ( $\mathrm{p}<.001, \mathrm{sd}=78)$ bulunmuştur. Ölçeğin yap1 geçerliği için uygulanan doğrulayıcı faktör analizinde orijinal formla tutarlı olarak 13 maddenin dört boyutta uyum verdiği görülmüştür $\left(x^{2}=153.37, s d=56, \mathrm{RMSEA}=.069\right.$, CFI=.91, IFI=.91, GFI=.94, SRMR=.080). Ölçeğin faktör yükleri .29 ile .58 arasında sıralanmakta olup; Cronbach Alfa iç tutarlılık güvenirlik katsayıları açıklık alt boyutu için .63, kendinden vazgeçme alt boyutu için .67, alçakgönüllülükle kendini değerlendirme alt boyutu için .72, diğerlerine odaklanma alt boyutu için .79 olarak bulunmuştur. Ölçüt geçerliği çalışmasında alçakgönüllülük ile affedicilik arasında pozitif ( $r=.52)$ ilişki olduğu görülmüştür. Test-tekrar test korelasyon katsayısı ölçeğin bütünü için $r=.63$ olarak bulunmuş; ayrıca ölçeğin düzeltilmiş madde-toplam korelasyonlarının .33 ile .53 arasında sıralandığı görülmüştür. Bu sonuçlara dayanarak Alçakgönüllülük Ölçeğinin psikoloji, psikiyatri ve eğitim alanında kullanılabilecek, geçerli ve güvenilir bir ölçme aracı olduğu söylenebilir.

Anahtar Kelimeler: Alçakgönüllülük; Geçerlik; Güvenirlik; Faktör analizi.

\title{
The Turkish Version of The Humility Scale: The Study of Validity and Reliability
}

\begin{abstract}
The aim of this research is to adapt the Humility Scale (Elliott 2010) to Turkish and to examine its psychometric qualifications. The research was conducted on total 648 (289 -+ 359) university students two different state universities. The validity and reliability of the scale was examined by test re-test, Cronbach alpha, exploratory and confirmatory factor analysis and criterion related validity methods. The Trait Forgivingness Scale was used for the criterion related validity together with Humility Scale. It is found that Kaiser-Meyer-Olkin (KMO) measure of sampling adequacy is 71.4 and value of Bartlett's test of sphericity $\chi 2=478,827(\mathrm{p}<.001, \mathrm{df}=78)$. Results of confirmatory factor analyses demonstrated that 13 items yielded four factors as original form and that the four-dimensionals model was well fit $\left(x^{2}=153.37, \quad s d=56, \quad R M S E A=.069, \quad \mathrm{CFI}=.91, \quad \mathrm{IFI}=.91, \mathrm{GFI}=.94\right.$, SRMR=.080). Factor loadings ranged from .29 ile .58. Cronbach Al-
\end{abstract}


pha internal consistency coefficient was found as .63 for openness sub-dimension, .67 for self-forgetfulness sub-dimension, .72 for modest self-assessment sub-dimension, .79 for focus on others subdimension and .81 for whole scale. In the concurrent validity significant relationships $(r=.52)$ were found between the Humility Scale and Trait Forgivingness Scale. Test-retest reliability coefficient was .63. Corrected item-total correlations ranged from .33 to .53. Overall results demonstrated that the Humility Scale could be named as a valid and reliable instrument that could be used in the field of psychology, psychiatry and education.

Keywords: Humility; Validity; Reliability; Factor analysis.

\section{Extended Summary}

\section{Purpose}

Humility refers to an undefended willingness to see the self exactly, containing both strengths and limitations. Although there is as yet little empirical research on the characteristics of humility, theory has begun to gather. For example, Tangney (2000) suggests that humility is marked by accurate estimations of one's self and abilities, willingness to acknowledge one's faults and limitations, openness to new ideas, and a tendency to appreciate benefits attributed to sources external to the self. The original form of Humility Scale developed by Elliott (2010) is a self-report measure of humility levels. Kaiser-Meyer-Olkin (KMO) measure of sampling adequacy of it was .73 and a significant result on Bartlett's test of sphericity $\chi 2=785.94$ $(p<.001)$. The results of explanatory factor analyses demonstrated that 13 items yielded four factors. Its factor loadings ranged from .43 ile .78. The internal consistency coefficient (Cronbach alpha) was found as .84 for whole scale. In the concurrent validity significant relation- 
ship ( $r=.34$ ) was found between the Humility Scale and Empathy Scale. Scoring of the measure was based on a 5 point degrees (Likert) type scale regarding the frequency with which the behavior of interest is exhibited where $1=$ strongly disagree, $5=$ strongly agree. Higher scores, therefore, indicate greater humility (range=13-65).

There is no scale to measure levels of humility in Turkey. Therefore, some scales are necessary for investigation of humility which is a very important concept in that reflection of personality (Elliott, 2010). The aim of this research was to adapt the Humility Scale (Elliott, 2010) to Turkish and to examine its psychometric qualifications.

\section{Methods}

\section{Participants}

Participants were a total of 648 university students (323 (49.9 \%) were female and 325 (50.1 \%) were male) who were enrolled in two different-state university (289 + 359 students), in Turkey. Their ages ranged from 18 to 35 years and the mean age of the participants was 23.4 years.

\section{Instrument}

The Trait Forgivingness Scale (TFS): The Trait Forgivingness Scale was developed by Berry, Worthington, O’Connor, Parrot III, \& Wade (2005). Turkish adaptation of this scale was done by Akın, Gediksiz and Akın (2012). This scale is a 10-items self-report measurement and consists of one factor. The results of confirmatory factor 
analysis indicated that the model was well fit and Chi-Square value $\left(x^{2}=106.47, \mathrm{sd}=32, \mathrm{p}<.001\right)$ which was calculated for the adaptation of the model was found to be significant. The goodness of fit index values of the model were RMSEA=.077, AGFI=.91, GFI=.95, CFI=.89, SRMR $=.062$. Factor loadings ranged from .32 to .61. The Cronbach alpha coefficient of the questionnaire was .67 and the corrected item-total correlations of TFS ranged from .26 to .43.

\section{Procedure}

Primarily the Humility Scale was translated into Turkish by five academicians from English Language and Literature department. Before validity and reliability studies, the correlations between Turkish and English forms were calculated in order to examine the language equivalency of the scale. In this study, exploratory factor analysis (EFA) was performed to examine the factor structure of the scale according to the data obtained from the Turkish students and confirmatory factor analysis (CFA) was executed to confirm the original scale's structure in Turkish culture. As reliability analysis re-test and internal consistency coefficients, the item-total correlations, and the differences between mean scores of upper $27 \%$ and lover $27 \%$ groups were examined. For the analysis of data SPSS 17 and LISREL 8.54 were utilized.

\section{Results}

There was a significant correlation between the original and Turkish version of the scale in the equivalency was .90 level. The exploratory factor analysis (EFA) studies were conducted with 289 
students. The confirmatory factor analysis applied to examine the factor validity of the scale was conducted with 359 students. Kaiser-Meyer-Olkin (KMO) measure of sampling adequacy was .71.4 and a significant result on Bartlett's test of sphericity $\chi 2=478,827(\mathrm{p}<.001$, $\mathrm{df}=78$ ). Results confirmatory factor analyses demonstrated that 13 items yielded four factors as original form and that the four-dimensional model was well fit $\left(x^{2}=153.37, \quad s d=56\right.$, RMSEA=.069, CFI=.91, IFI=.91, GFI=.94, SRMR=.080). Factor loadings ranged from .29 to .41. for openness subscale, .33 to .39 for self-forgetfulness subscale, 35 to 54 for modest self-assessment subscale, .38 to .58 for focus on others sub-scale. Cronbach alpha internal consistency coefficient was found as .63 for openness subscale, .67 for self-forgetfulness subscale, .72 for modest self-assessment subscale, .79 for focus on others subscale and .81 for whole scale. In the concurrent validity significant relationships $(\mathrm{r}=.52)$ were found between the Humility Scale and Trait Forgivingness Scale. The questionnaire was administered twice with an interval of 21 days between the two stages of administration. Test-retest reliability coefficient was calculated as .63. The corrected item-total correlations ranged from .33 to .53. According to these values, it can be said that the structural model of Humility Scale which consists of a factors was well fit to the Turkish culture.

\section{Discussion and Conclusion}

As a result, it is possible to say that the Humility Scale is a valid and reliable measurement tool to be used for the purpose of measuring 
humility levels of individuals. The scale can be used in researches into personality, and in the process of psychological counseling. The present research was carried out on the basis of data from university students. It would be possible to analyze the psychometric characteristics and the factor structure of the scale using in different samples in further studies. Moreover, it can be used as efficient instruments in order to assess empathy, altruism, self-esteem levels.

\section{Giriş}

Öznel iyi oluş kavramını yordayan tüm kavramlar pozitif psikolojinin çalışma alanına giren konulardır (Elliott, 2010). Alçakgönüllülük (humility) kavramı önceleri din felsefesi ve din psikolojisinin (Emmons ve Paloutzian, 2003) inceleme konusu iken son zamanlarda pozitif psikoloji (Elliott, 2010; Rowatt, Powers, Targhetta, Comer, Kennedy ve Labouf, 2006), kendilik psikolojisi ve sosyal psikolojinin de (self-psychology) (Emmons ve Paloutzian, 2003) ilgi alanına girmektedir.

Alçakgönüllülük (AG), kendi başarı ve yeteneklerini değerlendirmede ölçülü (Emmons, 1999), hatalarını, sınırlılıklarını ve eksikliklerini kabul eden (Tangney, 2000), yeni fikir ve tavsiyelere açık (Templeton, 1997), evrenin büyüklüğü karşısında kendini unutma eğiliminde olan (Tangney, 2000), başkalarını kendi ile bir tutan (Elliott, 2010), onlara sevgi ve saygı duyma (Exline ve Geyer, 2004) anlamına gelen ahlaki bir erdemdir (Rowatt, Powers, Targhetta, Comer, Kennedy ve Labouf, 2006). 
Alçakgönüllülük, kendini küçümseme değildir, ya da yanılgıdan uzak bir küçümsemedir. Ne olduğunu bilmemek değil, ne olmadığını bilmek ya da kabul etmektir. Alçak gönüllülükte gurur ve kendini beğenme yoktur. Alçakgönüllü insan, kendisini, gerçek değerinin altında değerlendirmeye eğilim gösterir; o başkasının karşısında varlıktan yoksun gibidir. Gururlu kimse görünüşte gerçek olan bir zayıf tarafını saklamaya kendisini zorlarken, alçakgönüllü insan, kendisindeki büyük bir kuvveti saklar (Hökelekli, 2007).

İnsanın doğuştan “büyüklenmeci kendilik duygusu”na sahip olduğu psikolojik bir gerçektir (Kohut, 2004). Bu duygu benmerkezci ve bencilce eğilim ve davranışların da kaynağını oluşturur. Eğer bu yönelim gittikçe artar ve azgınlaşarak yerleşik bir karakter halini alırsa o zaman "büyüklük hastalığı" başlar (Adler, 2004). Fakat bu duygu tamamen bastırılır, köreltilir ve benlik tamamen etkisiz ve silik bir duruma getirilirse, o zaman aşağılık duygusu, kendini reddetme eğilimleri ortaya çıkar. Kendini kabullenemeyen, aşağılık duygusu içerisine saplanıp kalan kimsede benlik saygısı gelişmez; korkak, çekingen ve beceriksiz bir karakter gelişir (Adler, 2000).

Alçakgönüllülük bir bakıma aşağılık duygusuna benzese de ondan çok farklıdır. Alçak gönüllülük bir kişilik yetersizliği ya da olumsuz kendilik duygusu içerisine saplanma durumundan çok farklı bir şeydir. Alçakgönüllü olmak, sefil, haysiyetsiz, onursuz ve şerefsiz bir hayat sürmek, hakaretlere katlanmak, kölece itaat etmek, hiçbir direnç ve irade gücü ortaya koymamak değildir. Derin bir bakış açısı içerisinde kendini üstün görmemek, ölçülü ve ılımlı bir kendilik algısına 
sahip olmak demektir. Makam, zenginlik, yetenek, şöhret, bedensel güç ve güzellik, başarı gibi gelip geçici şeylere gereğinden fazla önem vermemek, bunları kendinin ve başkalarının gelişmesi ve olgunlaşmasına hizmet ve yardım vasıtası olarak görmektir (Compte-Sponville, 2004).

Elliott (2010) alçakgönüllülüğü hem bir ahlaki erdem hem de psikolojik yapı olarak değerlendirmiş; alçakgönüllülüğün özellikle narsistik kişilik, yalnızlık ve empatiyle ilişkili olduğu varsayımıyla, bireylerin alçakgönüllülük düzeyini ölçmek için Alçakgönüllülük Ölçeğini geliştirmiştir. Uyum (ölçüt) geçerliliği çalışması için Narsistik Kişilik Envanteri, Hayat Doyumu Ölçeği ve Duygusal Empati Ölçeğini kullanmıştır. Ölçeğin yapı geçerliği için uygulanan açımlayıcı faktör analizinde KMO örneklem uygunluk katsayısı .73, Barlett testi $\chi 2$ değeri $785.94(p<.001)$ olarak bulunmuştur. Açımlayıcı faktör analizi sonucunda toplam varyansın \% 53.87'sini açıklayan dört boyutlu bir yapı elde edilmiştir. Maddelerin faktör yükleri, açıklık alt boyutu için .54 ile .78, kendinden vazgeçme için alt boyutu için. 68 ile .75, alçakgönüllülükle kendini değerlendirme için .43 ile .73, diğerlerine odaklanma için .50 ile .77 arasında değişmektedir. Ölçeğin ölçüt (uyum) geçerliliği çalışmasında alçakgönüllülük ölçeğinin alt ölçeklerinden açıklık ile Narsistik Kişilik Envanterinin özyeterlilik alt boyutu arasında $r=-.23$ negatif ilişki, empati ile $r=.34$ pozitif ilişki bulunmuştur. Kendinden vazgeçme Narsistik Kişilik Envanterinin üstünlük ve göstermecilik/teşhircilik alt boyutları arasında sırasıyla $r=.25$ ve $r=.26$ pozitif ilişki, psikolojik ayrıcalıkla $r=-.32$ negatif ilişki bulunmuştur. 
Alçakgönüllülükle kendini değerlendirme ile yalnızlık ve empati arasında sırasıyla $r=.45$ ve $r=.27$ pozitif, yaşam doyumu, psikolojik iyi olma ve özgüven arasında sırasıyla $r=-.30, r=-.41, r=-.58$ negatif ilişki bulunmuştur. Diğerlerine odaklanma ile dinî bağl1lık, psikolojik iyi olma, affedici kişilik yapısı ve empati arasında sırasıyla $r=.33, r=.30$, $r=.35, r=.47$ olumlu ilişki, psikolojik ayrıcalıkla $r=-.25$ negatif ilişki bulunmuştur. Ölçeğin Cronbach Alfa iç tutarlılık güvenirlik katsayısı ölçeğin bütünü için .84 olarak hesaplanmıştır. Geçerlik ve güvenirlik çalışmalarından elde edilen sonuçlar Alçakgönüllülük Ölçeğinin geçerlik ve güvenirliğinin sağlandığını göstermektedir. Ülkemizde alçakgönüllülük, özellikle din ve felsefe çalışmalarında, erdemli insanlarda bulunması gereken insani bir değer olarak tevazu ile eş anlamlı olarak incelenmiş ve bu çalışmaların çoğunda alçakgönüllülük söylemsel ifadelerle sınırlı kalmıştır. Bununla birlikte alçakgönüllülüğü psikolojik bir yapı olarak inceleyen herhangi bir çalışmaya rastlanmamış olması ve bireylerin alçakgönüllülük düzeylerini değerlendirebilecek herhangi bir ölçme aracının olmaması bu kavramla ilgili bir ölçme aracını ihtiyaç haline getirmektedir. Bu araştırmanın amacı Alçakgönüllülük Ölçeğini Türkçeye uyarlamak ve ölçeğin geçerlik ve güvenirliğini incelemektir.

\section{Yöntem}

\section{Çalışma Grubu}

Bu araştırma iki farklı üniversitede öğrenim gören toplamda 648 $(289+359)$ üniversite öğrencisi üzerinde yürütülmüştür. Öğrencilerin 133’ü din kültürü ve ahlak bilgisi öğretmenliği, 81'i fen bilgisi öğret- 
menliği, 124'ü okul öncesi öğretmenliği, 144'ü psikolojik danışmanlık ve rehberlik, 87'si sınıf öğretmenliği, 79'u sosyal bilgiler öğretmenliği bölümlerinde öğrenim görmektedir. Yaşları 18 ile 35 yaş arasında değişmekte ve yaş ortalaması 23.3 olan öğrencilerin 325'i (\% 50.1) erkek ve 323’ü (\% 49.9) kız öğrenciden oluşmaktadır.

\section{Kullanılan Ölçme Araçları}

Çalışmada veri toplamak amacıyla Alçakgönüllülük Ölçeğinin yanı sıra ölçüt (uyum) geçerliliği için Affedicilik Ölçeği kullanılmıştır. Ayrıca demografik bilgilere ulaşmak için Kişisel Bilgi Formu dağıtılmiştır.

Affedicilik Ölçeği (Trait Forgivingness Scale): Berry, Worthington, O’Connor, Parrot III ve Wade (2005) tarafından geliştirilen, Akın, Gediksiz ve Akın (2012) tarafından Türkçeye uyarlanan Affedicilik Ölçeği 10 madde ve tek boyuttan oluşan ve 5'li ("1" Hiç katılmiyorum- "5" Tamamen kat1liyorum) derecelendirmeye sahip, bireyin kendisi hakkında bilgi vermesi (self report) esasına dayalı olan bir ölçme aracıdır. Ölçekten elde edilebilecek en yüksek puan 50, en düşük puan ise 10'dur. Ölçek toplam bir affedicilik puanı vermektedir. Yükselen puanlar bireyin yüksek düzeyde affetme eğiliminin olduğunu göstermektedir. Ölçeğin 1., 3., 6., 7., 8. maddeleri ters kodlanmaktadır. Affedicilik Ölçeğinin yap1 geçerliği için 288 üniversite öğrencisinden elde edilen verilere doğrulayıcı faktör analizi uygulanmış ve ölçeğin orijinal formda olduğu gibi tek boyutta iyi uyum verdiği bulunmuştur $\left(x^{2}=106.47, s d=32, \mathrm{RMSEA}=.077, \mathrm{CFI}=.89, \mathrm{GFI}=.95, \mathrm{AGFI}=.91\right.$, SRMR=.062). Ölçeğin faktör yükleri .32 ile .61 arasında sıralanmak- 
tadır. Ölçeğin Cronbach Alfa iç tutarlılık güvenirlik katsayısı 67 olarak bulunmuş ve düzeltilmiş madde toplam korelasyon katsayılarının .26 ile .43 arasında değiştiği görülmüştür.

\section{İşlem}

Alçakgönüllülük Ölçeğinin uyarlama çalışması için ölçeği geliştiren Elliott ile e-mail yoluyla iletişim kurulmuş ve ölçeğin uyarlanabileceğine ilişkin gerekli izin alınmıştır. Ölçeğin Türkçeye çevrilme süreci belli aşamalardan oluşmaktadır. Öncelikle ölçek İngiliz Dili ve Edebiyatı ve Filoloji bölümü mezunu 5 dil uzmanı tarafindan Türkçeye çevrilmiş ve daha sonra bu Türkçe formlar tekrar İngilizceye çevrilerek İngilizce ve Türkçeyi bilen 23 kişiye uygulanarak iki form arasındaki tutarlılık incelenmiştir. Yine aynı öğretim üyeleri elde ettikleri Türkçe formlar üzerinde tartışarak anlam ve gramer açısından gerekli düzeltmeleri yapmış ve denemelik Türkçe form elde edilmiştir. Son aşamada bu form, psikolojik danışma ve rehberlik ve ölçme ve değerlendirme alanındaki 2 öğretim üyesine inceletilerek görüşleri doğrultusunda bazı değişiklikler yapılmıştır. Hazırlanan Türkçe form çoğaltılarak üniversite öğrencilerine gerekli açıklama yapıldıktan sonra uygulanmış ve formlar toplanarak, verilerin bilgisayar ortamına aktarılması sağlanmıştır. Alçakgönüllülük Ölçeğinin yapı geçerliği için elde edilen verilere açımlayıcı faktör analizi (AFA) ve doğrulayıcı faktör analizi (DFA) yapılmıştır. AFA çok sayıda değişkenden (maddeden) bu değişkenlerin birlikte açıklayabildikleri az sayıda tanımlanabilen anlamlı yapılara ulaşmayı hedefler (Büyüköztürk, 2011). DFA ise kuramsal bir temele dayanarak çeşitli değişkenlerden oluşturulan faktörlerin gerçek verilerle ne derece uyum gösterdiğini değerlendirme amacıyla kullanı- 
1ır. Yani DFA'da önceden belirlenmiş ya da kurgulanmış bir yapının toplanan verilerle ne derece doğrulandığı incelenmektedir (Sümer, 2000; Şimşek, 2007; Yılmaz ve Çelik, 2009). Bu çalışmada AFA uygulanmasının nedeni Alçakgönüllülük Ölçeğinin orijinal formunun Türk üniversite öğrencileri üzerinde uygulanıp uygulanmayacağını ve Türk öğrenciler üzerindeki yapısını açığa çıkarmak, DFA kullanılmasının nedeni orijinal formun faktör yapısının eğitim fakültesinde okuyan Türk öğrenciler üzerinde doğrulanıp doğrulanmadığını incelemektir (Büyüköztürk ve diğerleri, 2004). Uyum indekslerinde genelde olduğu gibi GFI, CFI, NFI, RFI ve IFI için >.90, RMR için <.05 ölçüt olarak alınmıştır (Hu ve Bentler, 1999). RMSEA için ise 0.08 kabul edilebilir uyum ve 0.05 mükemmel uyum değeri olarak kabul edilmiştir (Brown ve Cudeck, 1993). Ayrıca madde faktör yükleri için .40 ve yukarısı kriter olarak alınmış olup; çok az sayıda madde için .30 kriter olarak alınmıştır (Büyüköztürk, 2011; Kline, 1994; Nunnally ve Bemstein, 1994). Ortalama ve toplam puanlar arasındaki ilişkileri tespit etmek için Pearson Momentler Korelasyon Analizi uygulanmış olup; p<.01 önem düzeyi ölçüt olarak alınmıştır (Tezbaşaran, 1997). Alçakgönüllülük Ölçeğinin geçerlik ve güvenirlik analizleri için SPSS 17 ve LISREL 8.54 programları kullanılmıştır.

\section{Bulgular}

\section{Dilsel Eşdeğerlik}

İngilizce ve Türkçeyi çok iyi bilen 23 kişinin İngilizce form puanları ile Türkçe form puanları arasındaki korelasyon katsayısı açıklık alt boyutu için $r=.94$, kendinden vazgeçme alt boyutu için $r=.95$; al- 
çakgönüllülükle kendini değerlendirme alt boyutu için $r=.94$; diğerlerine odaklanma alt boyutu için $r=.96$, ölçeğin bütünün için $r=.95$ olarak bulunmuş ve sonuçlar Tablo 1'de gösterilmiştir.

Tablo 1. Orijinal form ile Türkçe Form Arasındaki İlişkiye Yönelik Pearson Momentler Korelasyon Analizi Sonuçları

\begin{tabular}{|c|c|c|c|c|}
\hline Alt boyutlar & $\mathbf{N}$ & $\mathbf{X}$ & $\begin{array}{c}\text { Standart } \\
\text { sapma }\end{array}$ & $\mathbf{r}$ \\
\hline Türkçe form (Açıklık alt boyutu) & 23 & 7.69 & 1.72 & \\
\hline İngilizce form (Açıklık alt boyutu) & 23 & 7.52 & 1.56 & $.94 * *$ \\
\hline $\begin{array}{l}\text { Türkçe form (Kendinden vazgeçme alt } \\
\text { boyutu) }\end{array}$ & 23 & 7.78 & 2.15 & \\
\hline $\begin{array}{l}\text { İngilizce form (Kendinden vazgeçme alt } \\
\text { boyutu) }\end{array}$ & 23 & 7.70 & 2.00 & $.95^{* * *}$ \\
\hline $\begin{array}{l}\text { Türkçe form (Alçakgönüllülükle kendimi } \\
\text { değerlendirme) }\end{array}$ & 23 & 11.95 & 2.93 & $.94^{* *}$ \\
\hline $\begin{array}{l}\text { İngilizce form (Alçakgönüllülükle kendimi } \\
\text { değerlendirme) }\end{array}$ & 23 & 12.17 & 2.50 & \\
\hline Türkçe form (Diğerlerine odaklanma) & 23 & 10.96 & 2.62 & $.96 * *$ \\
\hline İngilizce form (Diğerlerine odaklanma) & 23 & 11.13 & 2.45 & \\
\hline Türkçe form (Tüm ölçek) & 23 & 38.47 & 4.53 & $.95 * *$ \\
\hline İngilizce form (Tüm ölçek) & 23 & 38.61 & 3.56 & \\
\hline
\end{tabular}

$$
* * \mathrm{p}<.01
$$

\section{Yapı Geçerliği}

Ölçeğin yapı geçerliliği için öncelikle orta dereceli bir üniversitenin çeşitli bölümlerinde öğrenim gören 289 öğrenciden elde edilen 
verilerin, faktör analizine uygunluğunu tespit etmek amaciyla Kaiser-Meyer-Olkin (KMO) katsayısı hesaplanmış ve Barlett Spehericity testi yapılmıştır. Verilerin faktör analizine uygunluğu için KMO .60’dan yüksek ve Barlett testinin $\mathrm{p}<.01$ önem düzeyinde anlamlı ç1kması gerekmektedir (Büyüköztürk, 2011; Tabachnick ve Fidell, 2007). Yapılan analiz sonucu KMO örneklem uygunluk katsayısı .71.4 ve Barlett testi $\chi 2$ değeri 478,827 ( $<<.001, \mathrm{sd}=78)$ olarak bulunmuştur. Ölçeğin üniversite öğrencilerinden oluşan çalışma grubunda faktör yapısını ortaya koymak üzere açımlayıcı faktör analizi (AFA) yapılmıştır. Faktör analizi sonucunda ölçekte özdeğeri 1'den büyük olan birçok faktör ortaya çıkmıştır. Scree plot uygulaması incelendiğinde grafik eğrisinde ilk ani değişikliğin, dördüncü faktörde ortaya çıktığı gözlenmiştir. Bu durumda ölçeğin dört faktörlü olabileceği düşünülmüştür. Fakat Scree Plot eğrisi çok kullanışlı olmasına rağmen, faktör seçimlerinin tek başına bu ölçüte dayandırılması her zaman doğru olmaz (Field, 2002). Bu yüzden AFA yapılırken ölçeğin orijinali ile uyumlu dört faktörlü bir yapı elde etmek amaçlandığı için, temel bileşenler tekniği ile oblik döndürme faktör çözümlemesi sonuçları dört faktörlülükle sınırlandırılmıştır. Analiz sonucunda faktör yükleri .29 ile .58 arasında değişmekte olup; alt boyutlar toplam varyansın sırasıyla açıklık alt boyutu \% 9,36'sını, kendinden vazgeçme alt boyutu \% 12,78'ini, alçakgönüllülükle kendini değerlendirme alt boyutu \% 22,74'ünü, diğerlerine odaklanma alt boyutu \% 14,81'ini, ölçeğin tüm alt boyutları \% 59,69'unu açıklamaktadır ve sonuçlar Tablo 2'de verilmiştir. 
Tablo 2. AFA Faktör Yük ve Varyans Değerleri

\begin{tabular}{|c|c|c|c|c|}
\hline Madde & Açıklık & $\begin{array}{l}\text { Kendinden } \\
\text { vazgeçme }\end{array}$ & $\begin{array}{c}\text { Alçakgönüllülükle } \\
\text { kendini } \\
\text { değerlendirme }\end{array}$ & $\begin{array}{l}\text { Diğerlerine } \\
\text { odaklanma }\end{array}$ \\
\hline 1 & .29 & & & \\
\hline 2 & .31 & & & \\
\hline 3 & .41 & & & \\
\hline 4 & & .39 & & \\
\hline 5 & & .34 & & \\
\hline 6 & & .33 & & \\
\hline 7 & & & .35 & \\
\hline 8 & & & .47 & \\
\hline 9 & & & .48 & \\
\hline 10 & & & .54 & \\
\hline 11 & & & & .38 \\
\hline 12 & & & & .46 \\
\hline 13 & & & & .58 \\
\hline$\% 59,69$ & 9,36 & 12,78 & 22,74 & 14.81 \\
\hline
\end{tabular}

Doğrulayıcı faktör analizi (DFA): Alçakgönüllülük Ölçeğinin yapı geçerliği için orta dereceli farklı bir üniversitenin eğitim fakültesinde okuyan 359 öğrenciden elde edilen verilere uygulanan doğrulayıcı faktör analizinde dört boyutlu modelin uyum indeksi değerleri: $\chi 2=153.37, \quad s d=56, \quad \mathrm{RMSEA}=.069, \mathrm{CFI}=.91, \quad \mathrm{IFI}=.91, \mathrm{GFI}=.94$, $\mathrm{SRMR}=.080$ olarak bulunmuştur. Ölçeğe ait path analizi yapılmış ve sonuçlar Şekil 1'de verilmiştir. 


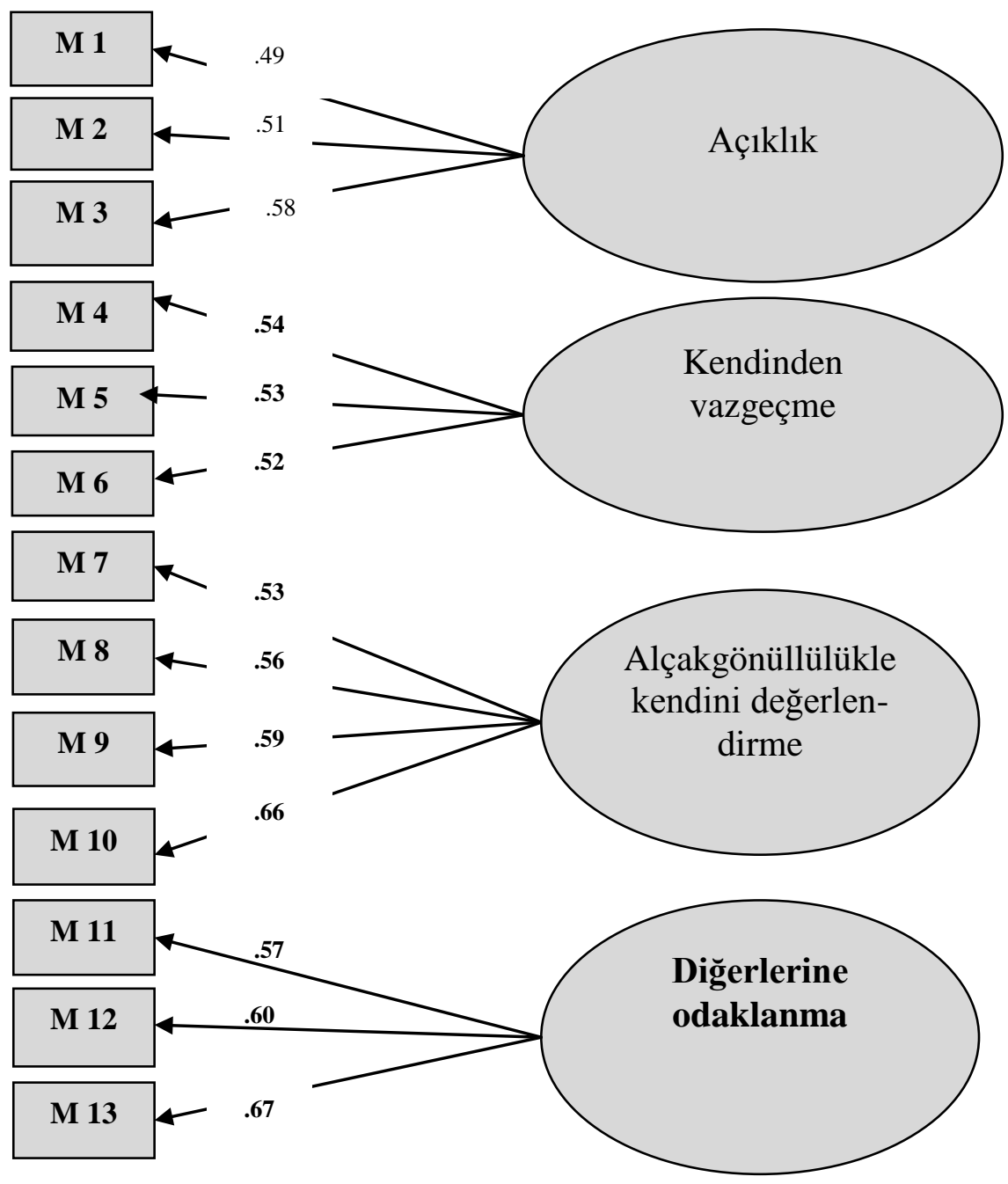

Şekil 1. Alçakgönüllülük Ölçeğine İlişkin Path Diagramı

Ölçüt geçerliliği: Ölçeğin ölçüt geçerliği çalışmasında alçakgönüllülük ile affedicilik (trait forgivingness) arasında pozitif ( $r=.53$ ) ilişki olduğu görülmüştür.

\section{Güvenirlik}

Alçakgönüllülük Cronbach Alfa iç tutarlılık güvenirlik katsay1- 
ları açıklık alt boyutu için .63, kendinden vazgeçme alt boyutu için .67, alçakgönüllülükle kendini değerlendirme alt boyutu için .72, diğerlerine odaklanma alt boyutu için .79 olarak bulunmuştur. Ayrıca ölçeğin test-tekrar test güvenirliği için ölçek 21 gün ara ile aynı çalışma grubundan 71 kişiye tekrar uygulandığında, iki uygulama arasındaki korelasyon katsayısı açıklık alt boyutu için $r=.94$, kendinden vazgeçme alt boyutu için $r=.88$; alçakgönüllülükle kendini değerlendirme alt boyutu için $r=.34$; diğerlerine odaklanma alt boyutu için $r=.33$, ölçeğin bütünü için $r=.63$ olarak bulunmuş ve sonuçlar Tablo 3'te gösterilmiştir.

Tablo 3. Alçakgönüllülük Ölçeğinin İlk ve İkinci Uygulamalar Arasındaki İlişkiye Ait Pearson Momentler Korelasyon Analizi Sonuçları

\begin{tabular}{|c|c|c|c|c|c|}
\hline Alt boyutlar & Uygulama & $\mathbf{N}$ & $\mathbf{X}$ & $\begin{array}{c}\text { Standart } \\
\text { sapma }\end{array}$ & $\mathbf{r}$ \\
\hline \multirow[b]{2}{*}{ Açıklık } & İlk uygulama & 71 & 7.70 & 1.72 & \multirow[b]{2}{*}{$.54^{* *}$} \\
\hline & İkinci uygulama & 71 & 7.43 & 1.85 & \\
\hline \multirow{2}{*}{$\begin{array}{l}\text { Kendinden vazgeçme } \\
\text { alt boyutu }\end{array}$} & İlk uygulama & 71 & 7.78 & 2.15 & \multirow{2}{*}{$.88 * *$} \\
\hline & İkinci uygulama & 71 & 7.39 & 2.23 & \\
\hline \multirow{2}{*}{$\begin{array}{l}\text { Alçakgönüllülükle } \\
\text { kendimi } \\
\text { değerlendirme }\end{array}$} & İlk uygulama & 71 & 11.95 & 2.92 & \multirow{2}{*}{$.34^{* *}$} \\
\hline & İkinci uygulama & 71 & 12.53 & 1.23 & \\
\hline \multirow{2}{*}{$\begin{array}{l}\text { Diğerlerine odak- } \\
\text { lanma }\end{array}$} & İlk uygulama & 71 & 10.96 & 2.61 & \multirow{2}{*}{$.33^{* *}$} \\
\hline & İkinci uygulama & 71 & 12.40 & 2.40 & \\
\hline \multirow[b]{2}{*}{ Tüm ölçek } & İlk uygulama & 71 & 38.45 & 4.52 & \multirow[b]{2}{*}{$.63^{* *}$} \\
\hline & İkinci uygulama & 71 & 40.02 & 3.77 & \\
\hline
\end{tabular}




\section{Madde Analizi}

Yapılan madde analizi sonucunda ölçeğin düzeltilmiş madde-toplam korelasyonları .33 ile .67 arasında sıralanmaktadır. Ayrıca toplam puanlara göre belirlenmiş \% 27'lik alt ve üst grupların madde puanlarındaki farklara ilişkin $\mathrm{t}(\mathrm{sd}=286)$ değerlerinin ise 2.15 ile 20.59 arasında değiştiği görülmüştür. Bulgular Tablo 4 ’te gösterilmiştir.

Tablo 4. Düzeltilmiş Madde Toplam Korelasyon Değerleri

\begin{tabular}{|c|c|c|c|c|}
\hline $\begin{array}{l}\text { Madde } \\
\text { No }\end{array}$ & Ortalama & $\begin{array}{l}\text { Standart } \\
\text { sapma }\end{array}$ & (Alt \%27-üst \%27) & $\begin{array}{l}\text { Düzeltilmiş } \\
\text { madde toplam } \\
\text { korelasyonları }\end{array}$ \\
\hline 1 & 1,76 & 1,20 & $2.15^{*}$ & .33 \\
\hline 2 & 3,57 & 1,13 & $2.75 * *$ & .34 \\
\hline 3 & 2,76 & 1,25 & $2.38 *$ & .44 \\
\hline 4 & 3,61 & 1,24 & $2.51 *$ & .42 \\
\hline 5 & 3,51 & 1,24 & $2.34 *$ & .41 \\
\hline 6 & 3,17 & 1,28 & $3.10 *$ & .40 \\
\hline 7 & 3,54 & 1,19 & $3.23 *$ & .43 \\
\hline 8 & 3,60 & 1,28 & $3.01 *$ & .50 \\
\hline 9 & 2,53 & 1,28 & $2.31 *$ & .53 \\
\hline 10 & 3,20 & 1,05 & $2.98 *$ & .66 \\
\hline 11 & 3,68 & 1,28 & $3.67 * *$ & .34 \\
\hline 12 & 3,66 & 1,25 & $5.54 * *$ & .56 \\
\hline 13 & 2,01 & 0,78 & $20.59 * *$ & .67 \\
\hline
\end{tabular}




\section{Tartışma}

$\mathrm{Bu}$ çalışmada üniversite öğrencilerinin alçakgönüllülük (humility) düzeylerini belirlemeye yönelik Alçakgönüllülük Ölçeğinin (Humility Scale) Türkçeye uyarlanması ve Türkçe formun geçerlik ve güvenirliğinin incelenmesi amaçlanmıştır. Geçerlik ve güvenirlik ça1ışmalarının yürütüldüğü gruplar sayı bakımından istatistiksel analizlerin gerektirdiği yeterliliktedir (Tabachnick ve Fidell, 2007). Ölçeğin Türkçe ve İngilizce formlarının dilsel açıdan eşdeğerliğini belirlemek amacıyla yapılan dilsel eşdeğerlik çalışmasından elde edilen sonuçlar iki formda yer alan maddelerin birbirleriyle yüksek düzeyde ilişkili olduğunu ortaya koymuştur. Buna göre Türkçe formda yer alan çeviri maddelerle İngilizce formda yer alan orijinal maddelerin benzeştiği ve ölçeğin dilsel eşdeğerliğinin sağlandığı söylenebilir.

Alçakgönüllülük Ölçeğinin geçerliği, yapı geçerliliği, ayırt edici geçerlik ve benzer ölçek geçerliği ile belirlenmiştir. Yapı geçerliliği için uygulanan faktör analizi sonucunda ölçeğin dört boyutlu olarak kabul edilebilir uyum verdiği görülmüştür. Faktör analizinde aynı yapıyı ölçen maddelerin belirlenmesinde, maddenin yer aldığ 1 faktör yük değerlerinin .40 ve daha yüksek değer alması ölçütü kullanılmakla birlikte, az sayıda madde için bu ölçüt .30'a kadar indirilebilir (Büyüköztürk, 2011; Kline, 1994; Nunnally ve Bemstein, 1994) kriteri esas alındığında ölçeğin madde faktör yüklerinin kabul edilebilir düzeyde olduğu söylenebilir. Bununla birlikte açıklanan varyans oranının \% 30'un üzerinde olmasının davranış bilimlerinde ölçek geliştirme ve uyarlama çalışmalarında yeterli görüldüğü (Büyüköztürk, 2011) dü- 
şünüldüğünde, ölçeğin yapı geçerliğinin sağlandığı görülmektedir. Ayırt edici geçerlik çalışması sonucunda ölçekte yer alan 13 maddenin alt grupla üst grubu birbirinden anlamlı düzeyde ayırt ettiği görülmüştür. Benzer ölçek geçerliği (ölçüt geçerliği) çalışması sonucunda ise ölçeğin geçerli olduğu sonucuna varılmıştır. Bu üç geçerlik çalışmasından elde dilen sonuçlar, araştırma literatüründe önerilen ve kabul edilebilir aralıklar arasında bulunmaktadır (Büyüköztürk, 2011). Alçakgönüllülük Ölçeğinin güvenirlik çalışmaları sonuçlarına bakıldığında ise Cronbach Alfa iç tutarlılık güvenirlik katsayısının .70'den yukarı olması araştırmalarda kullanılabilecek ölçme araçları için öngörülen güvenirlik düzeyinin .70 olduğu (Sipahi, Yurtkoru ve Çinko, 2008) dikkate alınırsa iç tutarlık güvenirliğinin iyi olduğu söylenebilir. Ayrıca madde analizi sonucunda ölçeğin madde-toplam korelasyon katsayılarının .30 ölçütünü karşıladığ1 görülmüştür. Madde-toplam korelasyon katsayılarının yorumlanmasında .30 ve daha yüksek olan maddelerin, bireyleri ölçülen özellik bakımından iyi derecede ayırt ettiği (Özdamar, 2004) göz önüne alındığında, madde toplam korelasyon katsayılarının yüksek düzeyde olduğu görülmektedir. Bunlarla birlikte test-tekrar test yöntemiyle elde edilen korelasyon katsayılarının kabul edilebilir düzeyde olmasıyla ölçeğin güvenirliğinin sağlandığı söylenebilir.

\section{Sonuçlar}

Alçakgönüllülük Ölçeğinin geçerlik ve güvenirlik çalışmalarından elde edilen bulgular, Türkçe’ye uyarlanan 13 maddelik ölçeğin üniversite öğrencilerinin alçakgönüllülük düzeylerini geçerli ve güve- 
nilir bir şekilde ölçmek amacıyla kullanılabileceğini göstermektedir. Cevaplama sistemi her ifade için ("1" Hiç katılmıorum- "5” Tamamen katılıyorum) arasında 5'li Likert şeklindedir. Her bir maddenin puanları 1 ile 5 arasında değişmektedir. 1., 2., 3., 4., 5., 6. maddeler puanlanırken ters kodlanmaktadır. Ölçekten alınabilecek en düşük puan 13, en yüksek puan ise 60'tır.

Alçakgönüllülük Ölçeğinin bireylerin alçakgönüllülük düzeyleri ile ilgili bilgi vermesi affedicilik, empati hakkında bilgi sağlamasının yanı sıra yapılacak psikolojik danışma ve terapi uygulamalarına da birçok kolaylık oluşturacağı düşünülmektedir. Bu çalışma üniversite öğrencilerinden elde edilen verilerle yürütülmüştür, fakat ölçeğin psikometrik özelliklerinin farklı çalışma gruplarıyla incelenmesi son derece önemlidir. Ayrıca, ölçeğin öz-aşkınlık, empatik eğilim, benlik saygısı, özgecilik düzeylerini belirleyen geçerli ve güvenilir ölçme araçlarıyla ilişkisine bakılabilir.

\section{Kaynakça}

Browne, M. W. ve Cudeck, R. (1993). Alternative ways of assessing model fit. K. A. Bollen ve J. S. Long, (Eds.), Testing structural equation models içinde (136-162). Newbury Park, CA: Sage.

Büyüköztürk, Ş. (2011). Veri analizi el kitabı. Ankara: Pegem A Yayıncılik.

Elliott, J. C. (2010). Humility: Development and analysis of a scale. Doktora tezi, University of Tennessee, Knoxville. 
Emmons, R. A. ve Paloutzian, R. F. (2003). The psychology of religion. Annual Review of Psychology, 54, 377-402. DOI: 10.1146/annurev.psych.54.101601.145024.

Emmons, R. A. (1999). Religion in the psychology of personality: An introduction. Journal of Personality, 67, 873-888.

Exline, J. J. ve Geyer, A. L. (2004). Perceptions of humility: A preliminary investigation. Self and Identity, 3, 95-114.

Field, A. (2002). Discovering statistics using SPSS. London: Sage Publications Ltd.

Hökelekli, H. (2007). Bir değer: Alçakgönüllülük (Tevazu). DEM Dergisi, 1(2), 114-119.

Hu, L. T. ve Bnetler, P. M. (1999). Cutoff criteria for fit indexes in covariance structural analysis: Conventional criteria versus new alternatives. Structural Equation Modeling, 6, 1-55.

Kashdan, T. B. ve Roberts, J. E. (2007). Social anxiety, depressive symptoms, and post-event rumination: Affective consequences and social contextual influences. Journal of Anxiety Disorders, 21, 284-301.

Kline, P. (1994). An esay guide to factor analysis. New York: Routledge.

Nunnally, J. C. ve Bernstein, I. H. (1994). Psychometric theory. New York: McGraw-Hill, INe.

Özdamar, K. (2004). Paket programlar ile istatistik veri analizi 1. Eskişehir: Kaan Kitabevi.

Rowatt, W. C., Powers, C., Targhetta, V., Comer, J., Kennedy, S. ve Labouf, J. (2006). Development and initial validation of an im- 
plicit measure of humility relative to arrogance. Journal of Positive Psychology, 1, 198-211.

Sipahi, B., Yurtkoru, E. S. ve Çinko, M. (2008). Sosyal bilimlerde SPSS'le veri analizi. İstanbul: Beta Basım Yayım Dağıtım.

Sümer, N. (2000). Yapısal eşitlik modelleri: Temel kavramlar ve örnek uygulamalar. Türk Psikoloji Yazıları, 3(6), 49-74.

Şimşek, Ö. F. (2007). Yapısal eşitlik modellemesine giriş: Temel ilkeler ve lisrel uygulamaları. Ankara: Ekinoks Yayınları.

Tabachnick, B. G. ve Fidell, L. S. (2007). Using multivariate statistics. Boston: Allyn and Bacon.

Tangney, J. P. (2000). Humility: theoretical perspectives, empirical findings and directions for future research. Journal of Social and Clinical Psychology, 19, 70-82.

Templeton, J. M. (1997). Worldwide laws of life. Philadelphia and London: Templeton Foundation Press.

Tezbaşaran, A. A. (1997). Likert tipi ölçek geliştirme kılavuzu. Ankara: Türk Psikologlar Derneği.

Yılmaz, V. ve Çelik, H. E. (2009). Lisrel ile yapısal eşitlik modellemesi-I: temel kavramlar, uygulamalar, programlama. Ankara: Pegem Akademi Yayınları. 